Please do not remove this page

RMIT

UNIVERSITY

\title{
Flight management system for unmanned reusable space vehicle atmospheric and re-entry trajectory optimisation
}

Ramasamy, Subramanian; Sangam, Manoj; Sabatini, Roberto; Gardi, Alessandro

https://researchrepository.rmit.edu.au/esploro/outputs/9921859997101341/filesAndLinks?institution=61RMIT_INST\&index=null

Ramasamy, S., Sangam, M., Sabatini, R., \& Gardi, A. (2014). Flight management system for unmanned reusable space vehicle atmospheric and re-entry trajectory optimisation. Applied Mechanics and Materials, 629, 304-309. https://doi.org/10.4028/www.scientific.net/AMM.629.304

Document Version: Accepted Manuscript

Published Version: https://doi.org/10.4028/www.scientific.net/AMM.629.304

Repository homepage: https://researchrepository.rmit.edu.au (C) 2014 by Trans Tech Publications Inc. All Rights Reserved

Downloaded On 2023/04/26 20:15:33 +1000 
Thank you for downloading this document from the RMIT Research Repository.

The RMIT Research Repository is an open access database showcasing the research outputs of RMIT University researchers.

RMIT Research Repository: http://researchbank.rmit.edu.au/

\section{Citation:}

Ramasamy, S, Sangam, M, Sabatini, R and Gardi, A 2014, 'Flight management system for unmanned reusable space vehicle atmospheric and re-entry trajectory optimisation', Applied Mechanics and Materials, vol. 629, pp. 304-309

See this record in the RMIT Research Repository at:

https://researchbank.rmit.edu.au/view/rmit:32018

Version: Accepted Manuscript

Copyright Statement: ㄷ 2014 by Trans Tech Publications Inc. All Rights Reserved

Link to Published Version:

http://dx.doi.org/10.4028/www.scientific.net/AMM.629.304 


\title{
Flight Management System for Unmanned Reusable Space Vehicle Atmospheric and Re-entry Trajectory Optimisation
}

\author{
Subramanian Ramasamy ${ }^{1}$, Manoj Sangam ${ }^{2}$, Roberto Sabatini ${ }^{3, a^{*}}$ and \\ Alessandro Gardi ${ }^{4}$ \\ ${ }^{1,3,4}$ School of Aerospace, Mechanical and Manufacturing Engineering, \\ RMIT University, Melbourne, VIC 3000, Australia \\ ${ }^{2}$ Department of Aerospace Engineering, \\ Cranfield University, Cranfield, MK43 OAL, United Kingdom \\ aroberto.sabatini@rmit.edu.au
}

\begin{abstract}
Keywords: flight management system, unmanned reusable space vehicle, trajectory optimisation, re-entry trajectory planning
\end{abstract}

\begin{abstract}
The design and trajectory computation algorithms of an innovative Flight Management System (FMS) for Unmanned Reusable Space Vehicle (URSV) are presented. The proposed FMS features a number of functionalities in common with modern aircraft FMS that enable flight planning in non-segregated airspace, as well as specific features for optimal trajectory generation and space segment monitoring of the flight mission. The general avionics architecture of the URSV is presented and the specific FMS algorithms are developed to cope with the flight vehicle optimal trajectory planning and monitoring. Simulation case studies are performed in a realistic operational scenario resulting in the rapid generation of feasible trajectories, ensuring no violation of the defined mission and vehicle dynamics constraints. Additionally, an error budget analysis is performed on the longitudinal profile trajectories to evaluate the performance of the URSV.
\end{abstract}

\section{Introduction}

Unmanned platforms are being increasingly adopted for both atmospheric and space applications, despite the access to the civil airspace remains currently restricted to segregated areas. Similar to the manned aircraft versions, Flight Management System (FMS) for unmanned platforms is the core avionics component to introduce extensive automation algorithms for a number of Navigation, Guidance and Control (NGC) tasks. In this paper we propose an innovative FMS design, which incorporates both conventional aircraft FMS capabilities [1 - 3] and spacecraft reentry trajectory generation algorithms, enabling non-segregated operations of an Unmanned Reusable Space Vehicles (URSV) in the civilian airspace. The Space Shuttle's entry guidance system [4] is used as a reference for re-entry trajectory planning. Guidance systems based on angle of attack $(\alpha)$ and bank angle $(\mu)$ modulations [5], on the quasi-equilibrium glide condition [6] and on the tracking of aerodynamic acceleration [7] have been developed. An improved methodology for re-entry trajectory planning based on creation of a drag acceleration profile as a function of energy has been developed [8] and is used as a baseline.

\section{Avionic Systems Architecture}

The avionic systems conceived for the URSV include an FMS, a Communications System (CS), a Flight Control System (FCS), a Mission Management System (MMS) for strategic/space orbital management, a Remote Piloting Management System (RPMS), which manages data exchanged via the CS to the remote Human Machine Interface and Interaction $\left(\mathrm{HMI}^{2}\right)$ station, an Obstacle Avoidance System (OAS) and a Rendezvous and Docking System (RVDS). The FCS translates the FMS/RPMS/OAS guidance or manual steering command inputs to actuators commands. Fig. 1 illustrates the functional architecture of the spacecraft avionic systems including the FMS subsystems listed in Table 1. 
Table 1. FMS subsystems and associated functions.

\begin{tabular}{|l|l|}
\hline FMS Subsystem & Function \\
\hline $\begin{array}{l}\text { Navigation Subsystem } \\
\text { (NS) }\end{array}$ & $\begin{array}{l}\text { Determines the state vector (position, attitude, linear and angular } \\
\text { velocities) of the spacecraft incorporating a sensor suite, data fusion } \\
\text { algorithms and processing logics. }\end{array}$ \\
\hline $\begin{array}{l}\text { Guidance Subsystem } \\
\text { (GS) }\end{array}$ & $\begin{array}{l}\text { Tracks the space vehicle's relative position from the validated } \\
\text { trajectory and calculates vertical, turn and reinsertion manoeuvres } \\
\text { wherever necessary. }\end{array}$ \\
\hline $\begin{array}{l}\text { Trajectory Planning and } \\
\text { (TP)imisation Subsystem }\end{array}$ & $\begin{array}{l}\text { Generates optimised atmospheric and re-entry trajectories based on } \\
\text { the updated state (NS), dynamics (VDPS), ATM constraints (CS) } \\
\text { and vehicle health (VHMS). A set of optimal trajectories is then } \\
\text { dispatched to the RPMS and the TNVS for pilot and ATM } \\
\text { evaluation and validation respectively. }\end{array}$ \\
\hline $\begin{array}{l}\text { Vehicle Dynamics and } \\
\text { Performance Subsystem } \\
\text { (VDPS) }\end{array}$ & $\begin{array}{l}\text { Performs dynamics and performance calculations based on a multi- } \\
\text { model architecture, which are primarily used by the trajectory } \\
\text { planning/optimisation loop and for vehicle health assessment tasks. }\end{array}$ \\
\hline $\begin{array}{l}\text { Trajectory Negotiation } \\
\text { and Validation } \\
\text { Subsystem (TNVS) }\end{array}$ & $\begin{array}{l}\text { Manages the negotiation and validation loops of 4-Dimensional } \\
\text { Trajectories (4DT) through the CS with the ground-based ATM } \\
\text { systems for safe operations in non-segregated airspace. }\end{array}$ \\
\hline $\begin{array}{l}\text { Surveillance Subsystem } \\
\text { (SS) }\end{array}$ & $\begin{array}{l}\text { Includes Automated Dependent Surveillance Broadcast (ADS-B) } \\
\text { receiver and transmitter (In and Out) as well as legacy aeronautical } \\
\text { surveillance devices. }\end{array}$ \\
\hline $\begin{array}{l}\text { Vehicle Data } \\
\text { Management Subsystem } \\
\text { (VDMS) }\end{array}$ & $\begin{array}{l}\text { Manages data storage of all the spacecraft parameters and interacts } \\
\text { with other subsystems for data retrieval and analysis. }\end{array}$ \\
\hline $\begin{array}{l}\text { Vehicle Health } \\
\text { (VHMS) }\end{array}$ & $\begin{array}{l}\text { Manages the health conditions of the spacecraft by monitoring the } \\
\text { data obtained from other components and dispatches reports to the } \\
\text { RPMS for downlinking via the CS. }\end{array}$ \\
\hline $\begin{array}{l}\text { Vehicle Integrity } \\
\text { (VIMS) }\end{array}$ & $\begin{array}{l}\text { Assesses and manages the integrity levels of Communication, } \\
\text { Navigation and Surveillance (CNS) systems and generates caution } \\
\text { and warning flags when the set threshold limits are exceeded. }\end{array}$ \\
\hline
\end{tabular}

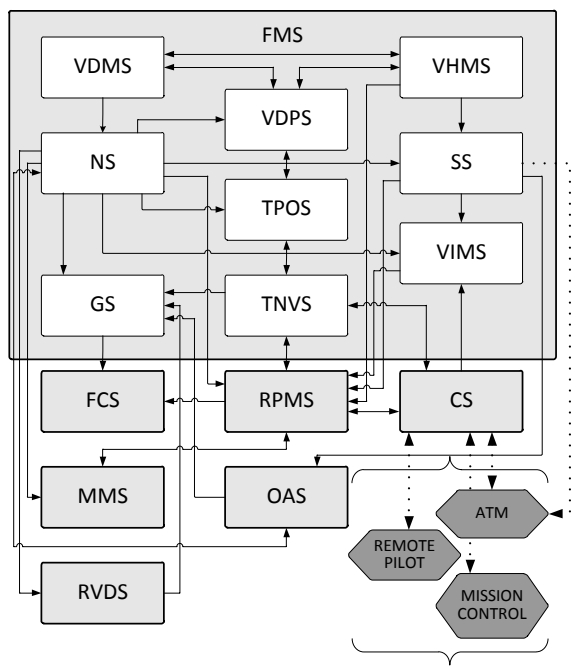

Fig. 1. Functional architecture of the URSV avionic systems. 
The FMS performs optimal trajectory planning, negotiation and tracking tasks. The FMS interacts with the Air Traffic Management (ATM) system, remote pilot and mission control stations on the ground.

\section{URSV Specifications}

The URSV flight phases are designed as: flight in the lower atmosphere (up to $50 \mathrm{~km}$ ), flight in the upper atmosphere until the Earth's environment (up to $250 \mathrm{~km}$ ), flight beyond the Earth's environment (above $250 \mathrm{~km}$ till the orbit), flight in the designed orbital, initial descent re-entry and flight in the upper atmosphere, pseudo-equilibrium glide and TAEM phase. The URSV characteristics including the mission, and constraint data for re-entry and Terminal Area Energy Management (TAEM), are presented in Table 2.

Table 2. URSV characteristics and scenario parameters.

\begin{tabular}{|c|c|}
\hline Parameter & Value \\
\hline Vehicle Mass & $16,177 \mathrm{~kg}$ \\
\hline Reference surface & $52.71 \mathrm{~m}^{2}$ \\
\hline Nose radius & $1 \mathrm{~m}$ \\
\hline Re-entry Altitude & $120 \mathrm{~km}$ \\
\hline Re-entry Velocity & $7764 \mathrm{~m} / \mathrm{s}$ \\
\hline TAEM Altitude & $24.38 \mathrm{~km}$ \\
\hline TAEM Velocity & $743 \mathrm{~m} / \mathrm{s}$ \\
\hline Maximum Heat Flux & $964 \mathrm{~kW} / \mathrm{m}^{2}$ \\
\hline Maximum g-load & $2.5 \mathrm{~g}$ \\
\hline Maximum Angle of Attack & $45^{\circ}$ \\
\hline Re-entry mass & $14,186 \mathrm{~kg}$ \\
\hline
\end{tabular}

\section{Re-entry Trajectory Generation}

The nominal re-entry phase of the URSV [9] begins at an altitude of around $120 \mathrm{~km}$ with a target speed of around Mach 25. The excessive energy is dissipated in order to attain the TAEM interface at the specified conditions. The re-entry is divided into two phases: initial descent and pseudoequilibrium glide. Initial descent takes place from an altitude of $120 \mathrm{~km}$ to $80 \mathrm{~km}$, where the atmospheric density is too low. During this phase, the vehicle experiences a controlled fall. Pseudoequilibrium glide is a major portion of re-entry. The flight path angle is very small and all of the path constraints are taken into account in this phase. Since there is limited power to change $\alpha$ over a major portion of the hypersonic re-entry, modulation of $\mu$ is considered as the key control parameter. Banking manoeuvres provide an efficient way to dissipate excess energy and at the same time makes it possible to achieve the desired range. Based on the entry conditions, the actual state vector, path and dynamic constraints, a reference trajectory is generated by the TPOS consisting of altitude-velocity profile, drag acceleration profile. Reference altitude and velocity profiles are calculated by integrating the Equations of Motion (EoM). A reference $\alpha$ profile is identified. The reentry energy corridor is then constructed based on the calculated upper and lower altitude/velocity limits. The necessary drag-energy profile is calculated and is used to determine the value of $\mu$. Based on the $\mu$ profile, the trajectory is integrated up to the TAEM interface and the cross-range at TAEM interface is estimated. The objective of bank reversal logic is to minimise such cross-range error. By applying $\alpha$ and $\mu$ modulation and integrating the EoM, the complete trajectory is generated. A 3-degrees-of-freedom (3-DoF) point mass model is assumed as main real-time model implemented in the VDPS for URSV re-entry dynamics. The EoM incorporate two control variables $\mathrm{u}=(\mu, \alpha)$. The six state variables are described as $\mathrm{x}=[\mathrm{r}, \theta, \varphi, \mathrm{V}, \gamma, \psi]$. The 3-DoF point mass model EoM, governing the vehicle states, are given by:

$$
\dot{\mathrm{r}}=\mathrm{V} \sin \gamma
$$




$$
\begin{aligned}
\dot{\theta} & =\frac{\mathrm{V} \cos \gamma \sin \psi}{\mathrm{r} \cos \varphi} \\
\dot{\varphi} & =\frac{\mathrm{V} \cos \gamma \cos \psi}{\mathrm{r}} \\
\dot{\mathrm{V}} & =-\mathrm{D}-\left(\sin \gamma / \mathrm{r}^{2}\right) \\
\dot{\gamma} & =\left(\frac{1}{\mathrm{~V}}\right)\left[\mathrm{L} \cos \mu+\left(\mathrm{V}^{2}-\frac{1}{\mathrm{r}}\right)\left(\frac{\cos \gamma}{\mathrm{r}}\right)\right] \\
\dot{\psi} & =\left(\frac{1}{\mathrm{~V}}\right)\left[\left(\frac{\mathrm{L} \sin \mu}{\cos \gamma}\right)+\left(\frac{\mathrm{V}^{2}}{\mathrm{r}}\right)(\cos \gamma \sin \psi \tan \varphi)\right]
\end{aligned}
$$

where ' $r$ ' is the radial distance from the centre of the Earth to the URSV in meters, ' $\theta$ ' is the geodetic longitude in radians, ' $\varphi$ ' is the geodetic latitude in radians, ' $V$ ' is the velocity in $\mathrm{m} / \mathrm{s}$ relative to the Earth surface, ' $\gamma$ ' is the flight path angle in radians and ' $\psi$ ' is the velocity azimuth angle in radians. The effect of wind and other atmospheric disturbances is assessed in the model validation. With the assumptions of no side-slip, non-rotating Earth and motion in vertical plane only (i.e., $\cos \mu=1$ ), the EoM are simplified. The path constraints pertaining to heat flux, dynamic pressure and g-load form the upper boundary of the entry corridor. In general, we have:

$$
\begin{aligned}
& \dot{\mathrm{Q}} \leq \mathrm{Q}_{\text {max }} \\
& |\mathrm{L} \cos \alpha+\mathrm{D} \sin \alpha| \leq \mathrm{n}_{\text {max }}
\end{aligned}
$$

where ' $\dot{Q}_{\max }$ ' is the max heat flux in $W / m^{2}$, ' $n_{\max }$ ' is the max g-load factor, ' $L$ ' and ' $D$ ' are the lift and drag aerodynamic accelerations in $\mathrm{m} / \mathrm{s}^{2}$. The lower boundary of the corridor is given by the steady glide equilibrium and the higher boundary of the corridor is given by the lower of the following maximum drag accelerations [9] expressed as:

$$
\left(\mathrm{g}-\frac{\mathrm{V}^{2}}{\mathrm{r}}\right) \frac{\mathrm{C}_{\mathrm{D}}}{\mathrm{C}_{\mathrm{L}}} \leq \mathrm{D} \leq \min \left\{\frac{\dot{\mathrm{Q}}_{\mathrm{max}}^{2} \mathrm{C}_{\mathrm{D}} \mathrm{S}}{2 \mathrm{~m} \mathrm{C}^{2} \mathrm{~V}^{4}} ; \frac{\mathrm{n}_{\max } \mathrm{g}}{\frac{\mathrm{C}_{\mathrm{L}}}{\mathrm{C}_{\mathrm{D}}} \cos \alpha+\sin \alpha} ; \frac{\mathrm{q}_{\max } \mathrm{C}_{\mathrm{D}} \mathrm{S}}{\mathrm{m}}\right\}
$$

where ' $\mathrm{q}_{\max }$ ' is the maximum dynamic pressure in $\mathrm{N} / \mathrm{m}^{2}$, ' $\mathrm{S}$ ' is the wing reference area in $\mathrm{m}^{2},{ }^{\text {' }} \mathrm{C}_{\mathrm{L}}$ ' is the lift coefficient, ' $\mathrm{C}_{\mathrm{D}}$ ' is the drag coefficient, ' $\mathrm{m}$ ' is the mass of the vehicle in $\mathrm{kg}$ and ' $\mathrm{g}$ ' is the acceleration due to gravity in $\mathrm{m} / \mathrm{s}^{2}$. The constant ' $\mathrm{C}$ ' is given by [9]:

$$
\mathrm{C}=\frac{\left(1.06584 \times 10^{8}\right)}{\sqrt{\mathrm{R}_{\mathrm{n}} \times \rho_{0}}} \frac{1}{(\mathrm{~g} \times \mathrm{r})^{1.5}}
$$

where ' $\rho_{0}$ ' is the Atmospheric density at sea level in $\mathrm{kg} / \mathrm{m}^{3}$ and ' $R_{\mathrm{n}}$ ' is the vehicle nose radius in $\mathrm{m}$. A reference drag-acceleration profile is then generated such that the URSV lies within the entry corridor and takes into account a specified trajectory length. A 3-segment linear profile is adopted for the reference drag acceleration profile [9], where $D_{1}(E), D_{2}(E)$ and $D_{3}(E)$ are the three drag segments. $D_{i}$ and $D_{f}$ are the initial and final values of drag acceleration respectively. $E_{i}$ and $E_{f}$ are the initial energy at re-entry and the final energy at TAEM interface respectively. $D_{c}$ is the constant drag of the intermediate segment. $E_{1}$ and $E_{2}$ are the energies corresponding to the boundary values of the constant drag. The trajectory length, ' $\mathrm{S}$ ' is given by:

$$
S=\int_{0}^{t} V d t=-\int_{E_{i}}^{E_{f}} \frac{1}{D(E)} d E=\frac{E_{1}-E_{i}}{D_{i}-D_{c}} \ln \frac{D_{c}}{D_{i}}+\frac{E_{1}-E_{2}}{D_{c}}+\frac{E_{f}-E_{2}}{D_{c}-D_{f}} \ln \frac{D_{f}}{D_{c}}
$$

By assuming an initial estimate of the trajectory length, the only unknown variable in the above equation is $D_{c}$, which is obtained by using the secant method [9]. Most of the re-entry algorithms assume a determined $\alpha$ profile. Though there is no specific method for determination of such profile, a general guideline is that $\alpha$ should be set close to its maximum value, $\alpha_{\max }$ during the initial part of re-entry and it should be switched to $\alpha_{(\mathrm{L} / \mathrm{D})_{\max }}$ at a determined altitude before TAEM interface. The value of $\mu$ is derived from the constructed drag acceleration profile. The second derivative of drag acceleration with respect to energy is given by $[8,9]$ :

$$
\mathrm{D}^{\prime \prime}=\mathrm{a}+\mathrm{b}\left(\frac{\mathrm{L}}{\mathrm{D}}\right) \cos \mu
$$


where:

$$
\begin{aligned}
& \mathrm{a}=\mathrm{D}\left(\frac{\mathrm{C}_{\mathrm{D}}^{\prime \prime}}{\mathrm{C}_{\mathrm{D}}}-\frac{\mathrm{C}_{\mathrm{D}}^{\prime 2}}{\mathrm{C}_{\mathrm{D}}^{2}}\right)+\mathrm{D}^{\prime}\left(\frac{\mathrm{C}_{\mathrm{D}}^{\prime}}{\mathrm{C}_{\mathrm{D}}}+\frac{2}{\mathrm{~V}^{2}}\right)-\frac{4 \mathrm{D}}{\mathrm{V}^{4}}+\frac{1}{\mathrm{DV}^{2}}\left(-\frac{1}{\rho} \frac{\partial \rho}{\partial \mathrm{r}}+\frac{2 \mathrm{~g}}{\mathrm{~V}^{2}}\right)\left(\mathrm{g}-\frac{\mathrm{V}^{2}}{\mathrm{r}}\right) \\
& \mathrm{b}=-\frac{1}{\mathrm{~V}^{2}}\left(-\frac{1}{\rho} \frac{\partial \rho}{\partial \mathrm{r}}+\frac{2 \mathrm{~g}}{\mathrm{~V}^{2}}\right)
\end{aligned}
$$

The heading of the vehicle relative to the desired heading at TAEM interface is continuously monitored and whenever the difference between the two exceeds a predefined threshold, the direction of $\mu$ is reversed. For evaluating the states with respect to tolerance values, error analysis was performed on the trajectories obtained in the longitudinal profile considering velocity, altitude and flight path angle deviations from the nominal value. The $2 \sigma$ error parameters used in the stochastic case are from $[10,11]$ and the $3-\mathrm{DoF}$ vertical profile error parameters are expressed as:

$$
\begin{aligned}
& \sigma_{\dot{V}}=\sqrt{\left(-\frac{1}{r^{2}} \cos \gamma\right)^{2} \sigma_{\gamma}^{2}+\left(\frac{2 \sin \gamma}{r^{3}}\right)^{2} \sigma_{r}^{2}+\left(\frac{\rho V^{2} S_{\text {ref }} \mathrm{C}_{(\mathrm{D}, \alpha)}}{2 m}\right)^{2} \sigma_{\alpha}^{2}} \\
& \sigma_{\dot{\mathrm{r}}}=\sqrt{(\sin \gamma)^{2} \sigma_{\mathrm{V}}{ }^{2}+(\mathrm{V} \cos \gamma)^{2} \sigma_{\gamma}{ }^{2}} \\
& \sigma_{\dot{\gamma}}=\sqrt{\left(\frac{\mathrm{L} \cos \mu}{\mathrm{V}^{2}}\right)^{2} \sigma_{\mathrm{V}}{ }^{2}+\left(-\frac{\mathrm{V} \cos \gamma}{\mathrm{r}^{2}}+\frac{\cos \gamma}{\mathrm{V} \cdot \mathrm{r}^{3}}\right)^{2} \sigma_{\mathrm{r}}^{2}+\left(-\frac{\mathrm{V} \sin \gamma}{\mathrm{r}}+\frac{\sin \gamma}{\mathrm{V} \cdot \mathrm{r}^{2}}\right)^{2} \sigma_{\gamma}{ }^{2}+\left(\frac{\rho \mathrm{V}^{2} \mathrm{~S}_{\mathrm{ref}} \mathrm{C}_{(\mathrm{L}, \alpha)}}{2 \mathrm{~m}}\right)^{2} \sigma_{\mu}{ }^{2}}
\end{aligned}
$$

where ' $\rho$ ' is the atmospheric density in $\mathrm{kg} / \mathrm{m}^{3}$ and ' $\mathrm{S}_{\text {ref }}$ ' is the reference surface area of the URSV in $\mathrm{m}^{2}$.

\section{Simulation Results}

After the reference altitude-velocity profile has been constructed imposing $\alpha$ to be constant at $45^{\circ}$ and $\mu$ to zero, an entry corridor is identified in the drag-energy plane and the reference 3 segment drag acceleration profile is constructed for the vehicle under consideration as illustrated in Fig. 2. The upper boundary corresponds to the maximum heat flux and maximum g-loads. The lower boundary corresponds to the minimum lift. The updated $\alpha$ and $\mu$ profiles are obtained after the drag-energy profile is created. Angle of attack is set to a maximum of $45^{\circ}$ during the initial part of re-entry to minimize heating and modulated near the TAEM interface to obtain the maximum lift-to-drag ratio. The total range covered in the re-entry phase is $9378 \mathrm{~km}$. By using Monte Carlo sampling technique, the errors in the vertical profile are analysed for 100 samples and the mean and standard deviation $[2 \sigma]$ values obtained for altitude, velocity and flight path angle are $[21.29 \mathrm{~m}$, $1.9937 \mathrm{~m} / \mathrm{s}, 0.0000745 \mathrm{radian}]$ and $[29.82 \mathrm{~m}, 2.4357 \mathrm{~m} / \mathrm{s}, 0.000616$ radian] respectively. The results obtained from evaluating the errors demonstrate that the deviations are always well within the reentry energy corridor.

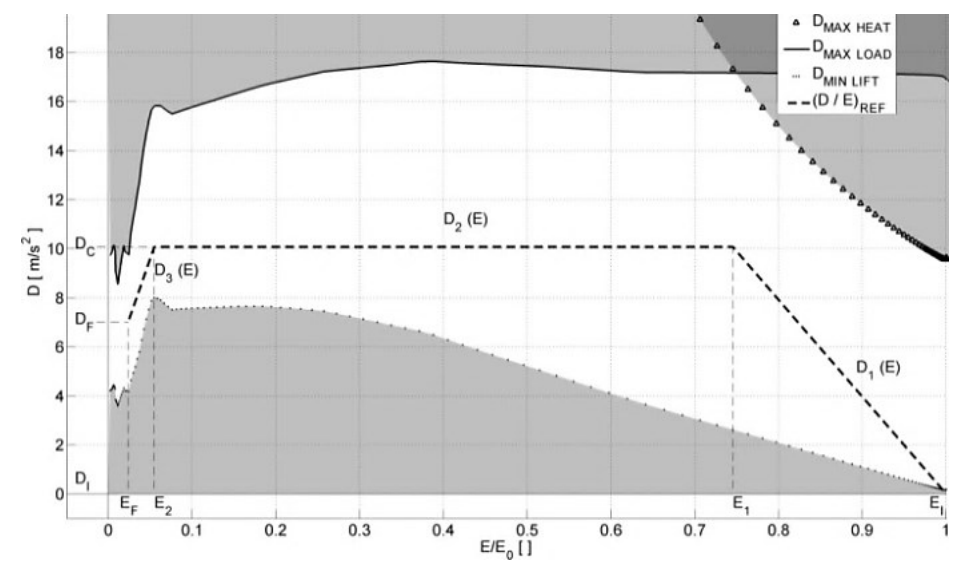

Fig. 2. Drag-energy profile construction. 


\section{Conclusions and Future Work}

The architecture of a Flight Management System (FMS) of an Unmanned Reusable Space Vehicle (URSV) was presented, with a special focus on functionalities for trajectory planning for atmospheric re-entry. The different flight phases of the space vehicle were identified and hypersonic re-entry and Terminal Area Energy Management (TAEM) were addressed as the two major phases of the atmospheric re-entry. A novel on-board trajectory planning algorithm based on the dragenergy profile was developed for the hypersonic re-entry phase. Angle of attack $(\alpha)$ and bank angle $(\mu)$ modulation were used to shape the re-entry trajectory. Simulation case studies were performed for the re-entry phase and the results demonstrated the FMS suitability to generate efficient trajectory profiles that satisfy the given constraints. Future work is envisaged in including all other flight phases including orbital flight and to address the future 4D Trajectory Based Operations (4DTBO) in an Environmentally Sustainable aviation (ESA) context [12].

\section{References}

[1] S. Liden, The Evolution of Flight Management Systems, AIAA/IEEE $13^{\text {th }}$ Digital Avionics Systems Conference, Phoenix, AZ, USA. (1994) DOI: 10.1109/DASC.1994.369487

[2] J. Sorensen, The Flight Planning - Flight Management Connection, Proceedings of the American Control Conference, San Diego, CA, USA. (1984)

[3] A. Herndon, M. Cramer, K. Sprong and R. Mayer, Analysis of Advanced Flight Management Systems (FMS), Flight Management Computer (FMC) Field Observations Trials, Vertical Path, $26^{\text {th }}$ Digital Avionics Systems Conference, Virginia, USA. (2007) DOI: 10.1109/DASC.2007.4391899

[4] J. Harpold and C. Graves, Shuttle Entry Guidance, Journal of the Astronautical Sciences, 37(3), pp. 239-268. (1979)

[5] J. Leavitt and K. Mease, Feasible Trajectory Generation for Atmospheric Entry Guidance, Journal of Guidance, Control and Dynamics, 30(2), pp. 473-481 . (2007) DOI: 10.2514/1.23034

[6] Z. Shen and P. Lu, Onboard Generation of Three-Dimensional Constrained Entry Trajectories, Journal of Guidance, Control and Dynamics, 26(1), pp. 111-121. (2003) DOI: 10.2514/2.5021

[7] A. Saraf, J. Leavitt, D. Chen and K. Mease, Design and Evaluation of an Acceleration Guidance Algorithm for Entry, Journal of Spacecraft and Rockets, 41(6), pp. 986-996. (2004) DOI: $10.2514 / 1.11015$

[8] K. Mease, D. Chen, P. Teufel and H. Schonenberger, Reduced-Order Entry Trajectory Planning for Acceleration Guidance, Journal of Guidance, Control and Dynamics, 25(2), pp. 257-266. (2002) DOI: $10.2514 / 2.4906$

[9] M. Sangam, R. Sabatini, S. Ramasamy and A. Gardi, Advanced Flight Management System for an Unmanned Reusable Space Vehicle, International Journal of Unmanned Systems Engineering, 1(3), pp. 48-67. (2013) DOI: 10.14323/ijuseng.2013.11

[10] R. Sabatini, A. Kaharkar, C. Bartel and T. Shaid, Carrier-phase GNSS Attitude Determination and Control for Small UAV Applications, Journal of Aeronautics and Aerospace Engineering, 2(4). (2013) DOI: 10.4172/2168-9792.1000120

[11] R. Sabatini, M.A. Richardson, C. Bartel, A. Kaharkar, T. Shaid, L. Rodriguez and A. Gardi, A Low-cost Vision Based Navigation System for Small Size Unmanned Aerial Vehicle Applications, Journal of Aeronautics and Aerospace Engineering, 2(3). (2013) DOI: 10.4172/2168-9792.1000110

[12] S. Ramasamy, R. Sabatini, A. Gardi and Y. Liu, Novel Flight Management System for Real Time 4-Dimensional Trajectory Based Operations, AIAA Guidance, Navigation \& Control Conference, Boston, Massachusetts, USA. (2013) DOI: 10.2514/6.2013-4763 
部

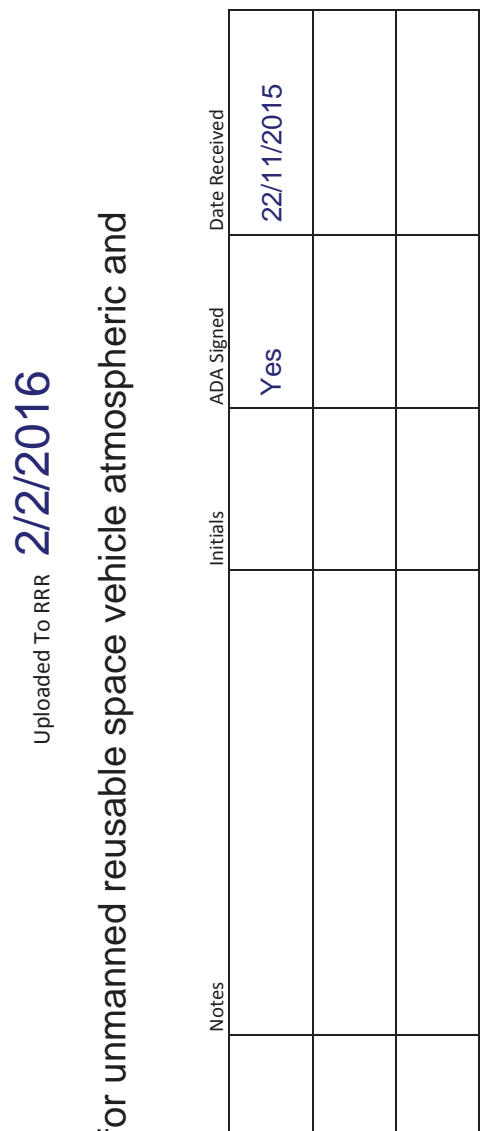

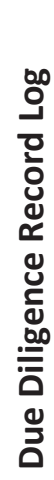

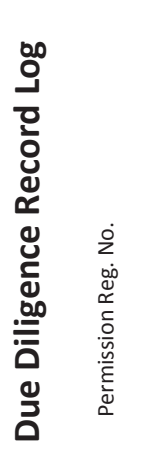

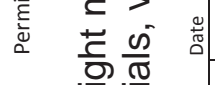

핀

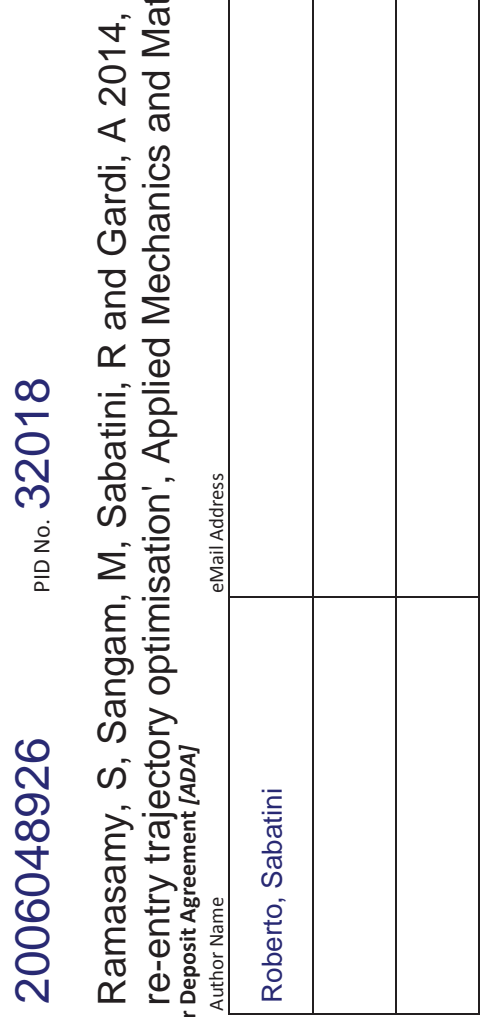

, 11
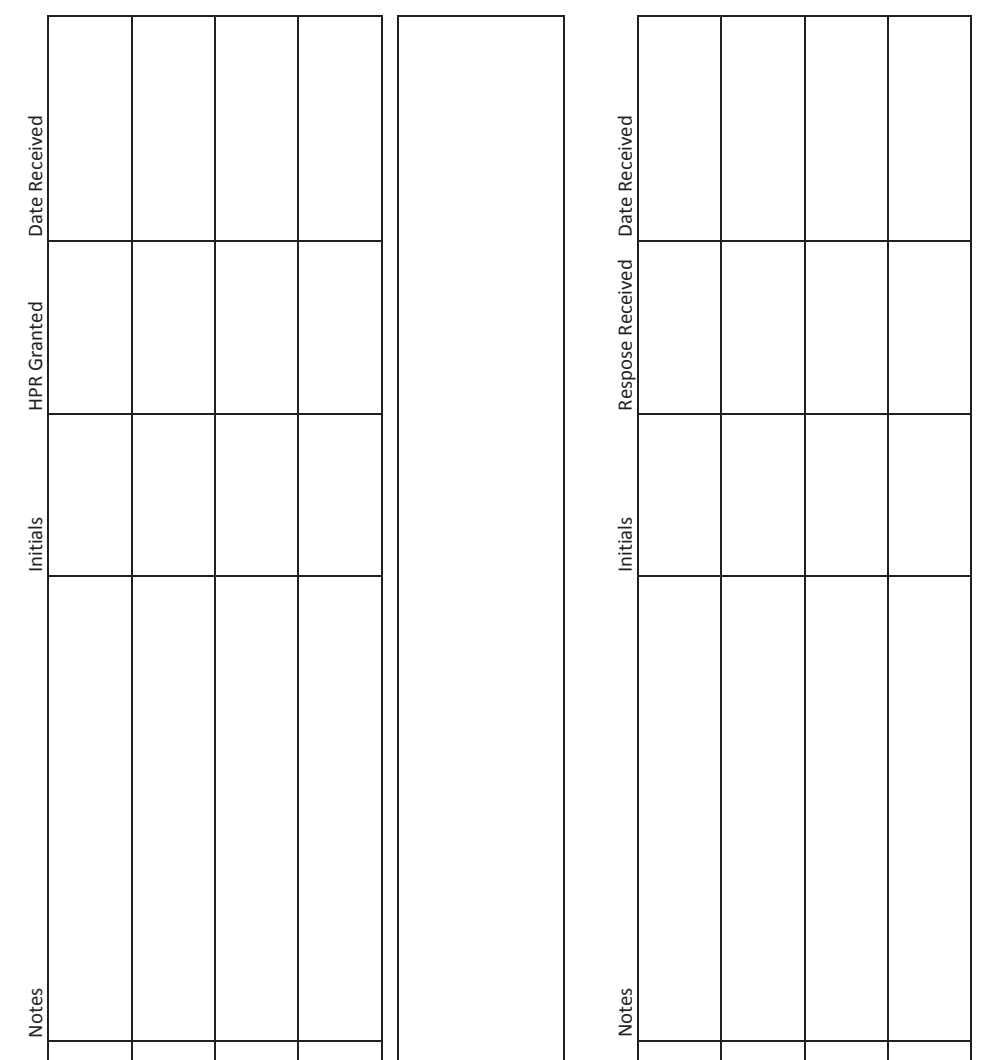

$\stackrel{0}{0}$
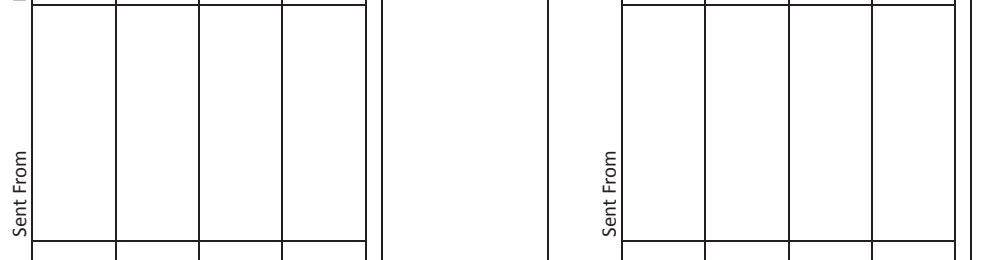

ะั๊
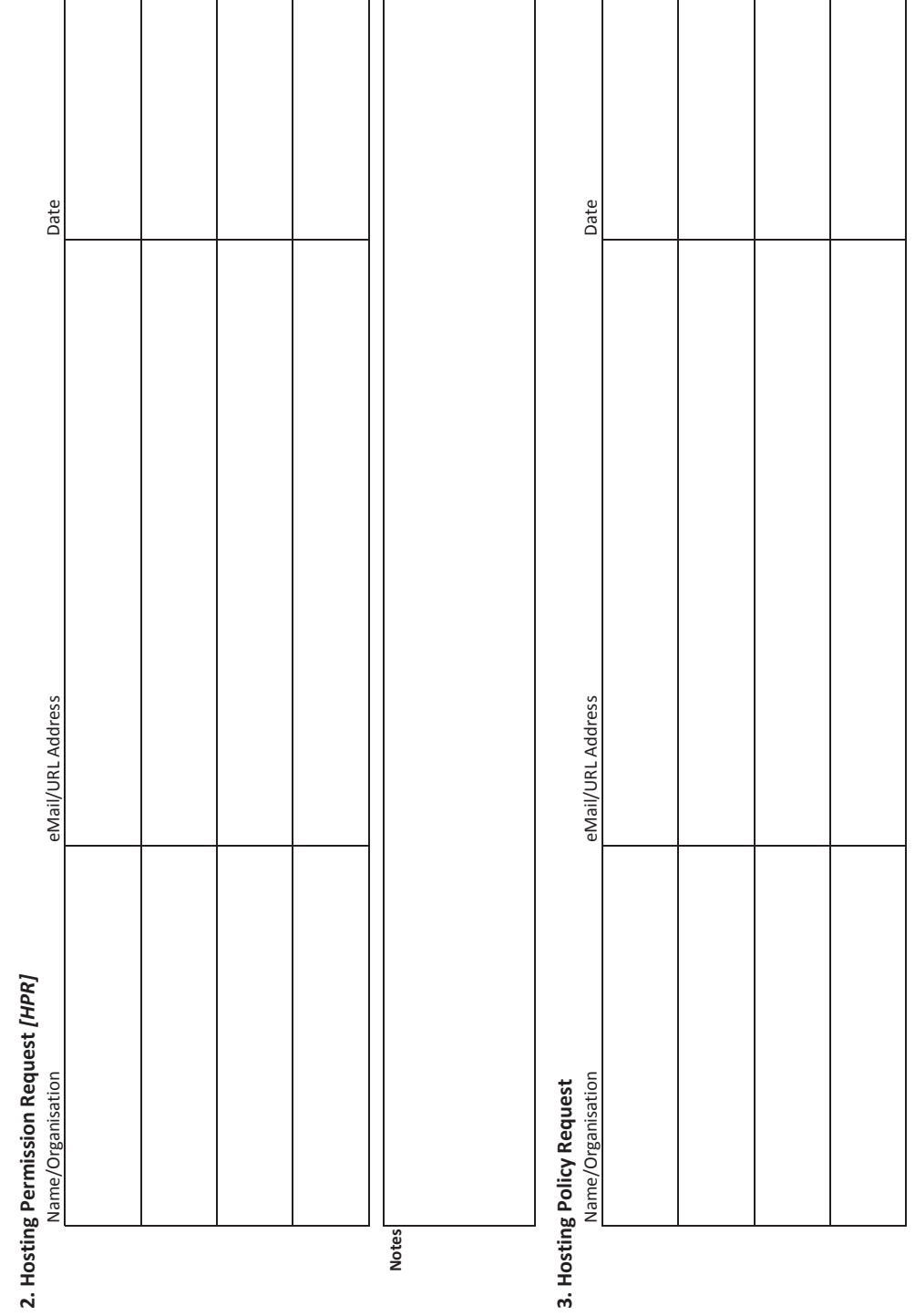


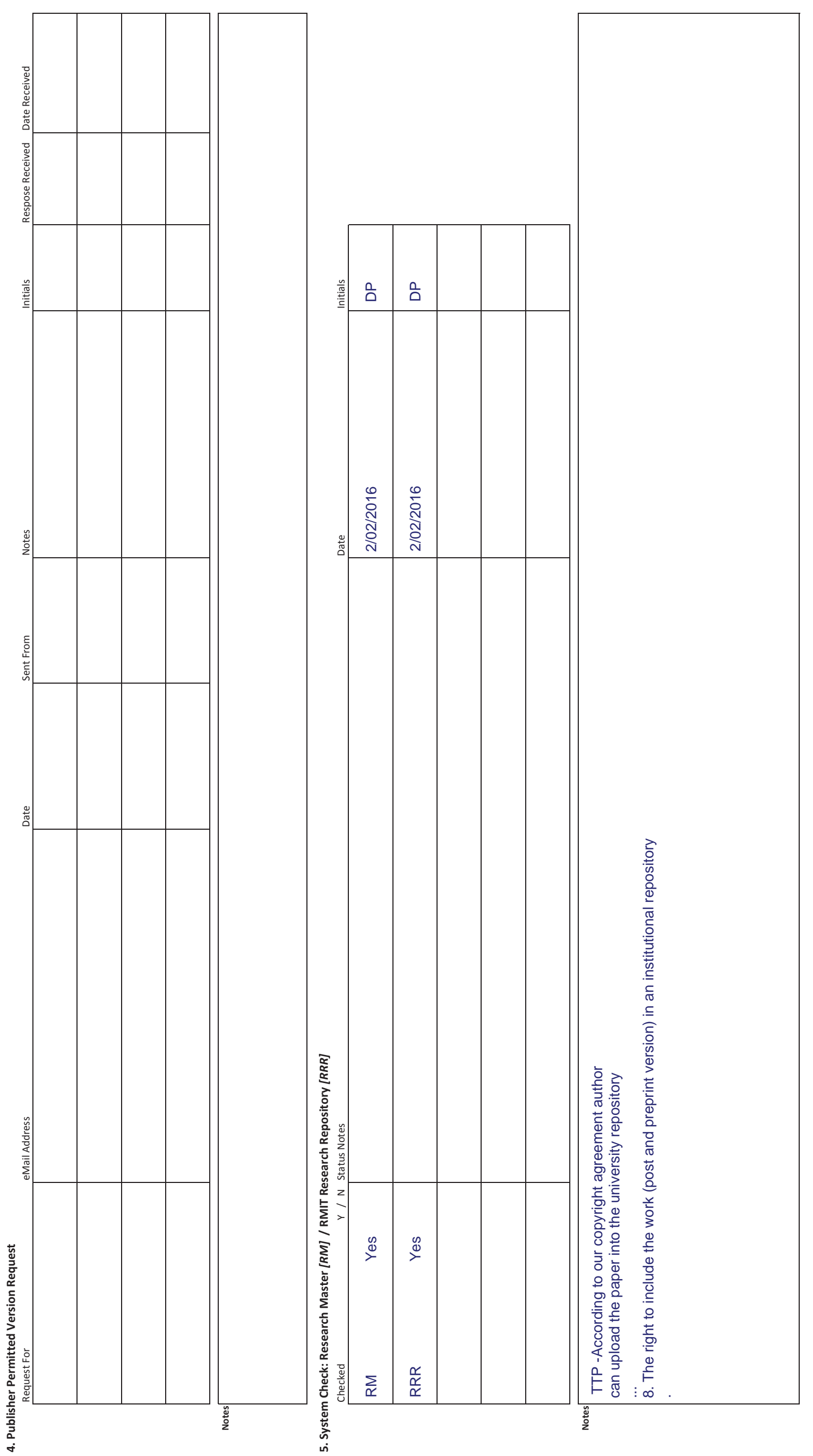




\title{
Flight Management System for Unmanned Reusable Space Vehicle Atmospheric and Re-entry Trajectory Optimisation
}

\author{
Subramanian Ramasamy ${ }^{1}$, Manoj Sangam ${ }^{2}$, Roberto Sabatini ${ }^{3, a^{*}}$ and \\ Alessandro Gardi ${ }^{4}$ \\ ${ }^{1,3,4}$ School of Aerospace, Mechanical and Manufacturing Engineering, \\ RMIT University, Melbourne, VIC 3000, Australia \\ ${ }^{2}$ Department of Aerospace Engineering, \\ Cranfield University, Cranfield, MK43 OAL, United Kingdom \\ aroberto.sabatini@rmit.edu.au
}

\begin{abstract}
Keywords: flight management system, unmanned reusable space vehicle, trajectory optimisation, re-entry trajectory planning
\end{abstract}

\begin{abstract}
The design and trajectory computation algorithms of an innovative Flight Management System (FMS) for Unmanned Reusable Space Vehicle (URSV) are presented. The proposed FMS features a number of functionalities in common with modern aircraft FMS that enable flight planning in non-segregated airspace, as well as specific features for optimal trajectory generation and space segment monitoring of the flight mission. The general avionics architecture of the URSV is presented and the specific FMS algorithms are developed to cope with the flight vehicle optimal trajectory planning and monitoring. Simulation case studies are performed in a realistic operational scenario resulting in the rapid generation of feasible trajectories, ensuring no violation of the defined mission and vehicle dynamics constraints. Additionally, an error budget analysis is performed on the longitudinal profile trajectories to evaluate the performance of the URSV.
\end{abstract}

\section{Introduction}

Unmanned platforms are being increasingly adopted for both atmospheric and space applications, despite the access to the civil airspace remains currently restricted to segregated areas. Similar to the manned aircraft versions, Flight Management System (FMS) for unmanned platforms is the core avionics component to introduce extensive automation algorithms for a number of Navigation, Guidance and Control (NGC) tasks. In this paper we propose an innovative FMS design, which incorporates both conventional aircraft FMS capabilities [1 - 3] and spacecraft reentry trajectory generation algorithms, enabling non-segregated operations of an Unmanned Reusable Space Vehicles (URSV) in the civilian airspace. The Space Shuttle's entry guidance system [4] is used as a reference for re-entry trajectory planning. Guidance systems based on angle of attack $(\alpha)$ and bank angle $(\mu)$ modulations [5], on the quasi-equilibrium glide condition [6] and on the tracking of aerodynamic acceleration [7] have been developed. An improved methodology for re-entry trajectory planning based on creation of a drag acceleration profile as a function of energy has been developed [8] and is used as a baseline.

\section{Avionic Systems Architecture}

The avionic systems conceived for the URSV include an FMS, a Communications System (CS), a Flight Control System (FCS), a Mission Management System (MMS) for strategic/space orbital management, a Remote Piloting Management System (RPMS), which manages data exchanged via the CS to the remote Human Machine Interface and Interaction ( $\left.\mathrm{HMI}^{2}\right)$ station, an Obstacle Avoidance System (OAS) and a Rendezvous and Docking System (RVDS). The FCS translates the FMS/RPMS/OAS guidance or manual steering command inputs to actuators commands. Fig. 1 illustrates the functional architecture of the spacecraft avionic systems including the FMS subsystems listed in Table 1. 
Table 1. FMS subsystems and associated functions.

\begin{tabular}{|l|l|}
\hline FMS Subsystem & Function \\
\hline $\begin{array}{l}\text { Navigation Subsystem } \\
\text { (NS) }\end{array}$ & $\begin{array}{l}\text { Determines the state vector (position, attitude, linear and angular } \\
\text { velocities) of the spacecraft incorporating a sensor suite, data fusion } \\
\text { algorithms and processing logics. }\end{array}$ \\
\hline $\begin{array}{l}\text { Guidance Subsystem } \\
\text { (GS) }\end{array}$ & $\begin{array}{l}\text { Tracks the space vehicle's relative position from the validated } \\
\text { trajectory and calculates vertical, turn and reinsertion manoeuvres } \\
\text { wherever necessary. }\end{array}$ \\
\hline $\begin{array}{l}\text { Trajectory Planning and } \\
\text { Optimisation Subsystem }\end{array}$ & $\begin{array}{l}\text { Generates optimised atmospheric and re-entry trajectories based on } \\
\text { the updated state (NS), dynamics (VDPS), ATM constraints (CS) } \\
\text { and vehicle health (VHMS). A set of optimal trajectories is then } \\
\text { dispatched to the RPMS and the TNVS for pilot and ATM } \\
\text { evaluation and validation respectively. }\end{array}$ \\
\hline $\begin{array}{l}\text { Vehicle Dynamics and } \\
\text { Performance Subsystem } \\
\text { (VDPS) }\end{array}$ & $\begin{array}{l}\text { Performs dynamics and performance calculations based on a multi- } \\
\text { model architecture, which are primarily used by the trajectory } \\
\text { planning/optimisation loop and for vehicle health assessment tasks. }\end{array}$ \\
\hline $\begin{array}{l}\text { Trajectory Negotiation } \\
\text { and Validation } \\
\text { Subsystem (TNVS) }\end{array}$ & $\begin{array}{l}\text { Manages the negotiation and validation loops of 4-Dimensional } \\
\text { Trajectories (4DT) through the CS with the ground-based ATM } \\
\text { systems for safe operations in non-segregated airspace. }\end{array}$ \\
\hline $\begin{array}{l}\text { Surveillance Subsystem } \\
\text { (SS) }\end{array}$ & $\begin{array}{l}\text { Includes Automated Dependent Surveillance Broadcast (ADS-B) } \\
\text { receiver and transmitter (In and Out) as well as legacy aeronautical } \\
\text { surveillance devices. }\end{array}$ \\
\hline $\begin{array}{l}\text { Vehicle Data } \\
\text { Management Subsystem } \\
\text { (VDMS) }\end{array}$ & $\begin{array}{l}\text { Manages data storage of all the spacecraft parameters and interacts } \\
\text { with other subsystems for data retrieval and analysis. }\end{array}$ \\
\hline $\begin{array}{l}\text { Vehicle Health } \\
\text { Management Subsystem } \\
\text { VHMS) }\end{array}$ & $\begin{array}{l}\text { Manages the health conditions of the spacecraft by monitoring the } \\
\text { data obtained from other components and dispatches reports to the } \\
\text { RPMS for downlinking via the CS. }\end{array}$ \\
\hline $\begin{array}{l}\text { Vehicle Integrity } \\
\text { Management System }\end{array}$ & $\begin{array}{l}\text { Assesses and manages the integrity levels of Communication, } \\
\text { Navigation and Surveillance (CNS) systems and generates caution } \\
\text { and warning flags when the set threshold limits are exceeded. }\end{array}$ \\
\hline
\end{tabular}

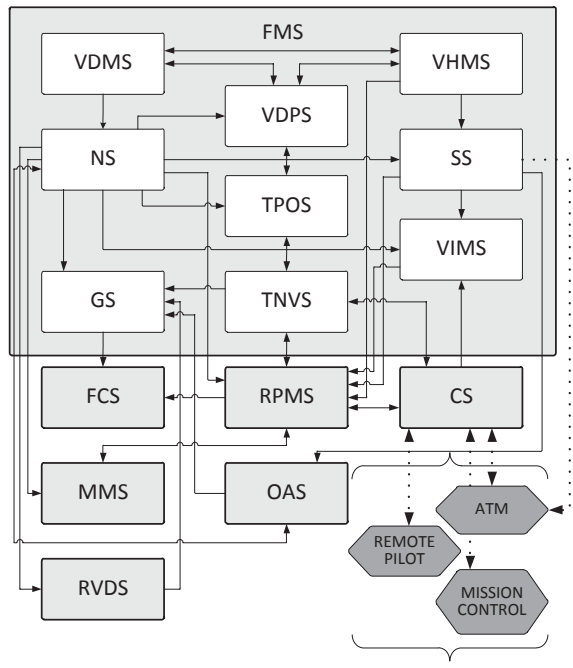

Fig. 1. Functional architecture of the URSV avionic systems. 
The FMS performs optimal trajectory planning, negotiation and tracking tasks. The FMS interacts with the Air Traffic Management (ATM) system, remote pilot and mission control stations on the ground.

\section{URSV Specifications}

The URSV flight phases are designed as: flight in the lower atmosphere (up to $50 \mathrm{~km}$ ), flight in the upper atmosphere until the Earth's environment (up to $250 \mathrm{~km}$ ), flight beyond the Earth's environment (above $250 \mathrm{~km}$ till the orbit), flight in the designed orbital, initial descent re-entry and flight in the upper atmosphere, pseudo-equilibrium glide and TAEM phase. The URSV characteristics including the mission, and constraint data for re-entry and Terminal Area Energy Management (TAEM), are presented in Table 2.

Table 2. URSV characteristics and scenario parameters.

\begin{tabular}{|c|c|}
\hline Parameter & Value \\
\hline Vehicle Mass & $16,177 \mathrm{~kg}$ \\
\hline Reference surface & $52.71 \mathrm{~m}^{2}$ \\
\hline Nose radius & $1 \mathrm{~m}$ \\
\hline Re-entry Altitude & $120 \mathrm{~km}$ \\
\hline Re-entry Velocity & $7764 \mathrm{~m} / \mathrm{s}$ \\
\hline TAEM Altitude & $24.38 \mathrm{~km}$ \\
\hline TAEM Velocity & $743 \mathrm{~m} / \mathrm{s}$ \\
\hline Maximum Heat Flux & $964 \mathrm{~kW} / \mathrm{m}^{2}$ \\
\hline Maximum g-load & $2.5 \mathrm{~g}$ \\
\hline Maximum Angle of Attack & $45^{\circ}$ \\
\hline Re-entry mass & $14,186 \mathrm{~kg}$ \\
\hline
\end{tabular}

\section{Re-entry Trajectory Generation}

The nominal re-entry phase of the URSV [9] begins at an altitude of around $120 \mathrm{~km}$ with a target speed of around Mach 25. The excessive energy is dissipated in order to attain the TAEM interface at the specified conditions. The re-entry is divided into two phases: initial descent and pseudoequilibrium glide. Initial descent takes place from an altitude of $120 \mathrm{~km}$ to $80 \mathrm{~km}$, where the atmospheric density is too low. During this phase, the vehicle experiences a controlled fall. Pseudoequilibrium glide is a major portion of re-entry. The flight path angle is very small and all of the path constraints are taken into account in this phase. Since there is limited power to change $\alpha$ over a major portion of the hypersonic re-entry, modulation of $\mu$ is considered as the key control parameter. Banking manoeuvres provide an efficient way to dissipate excess energy and at the same time makes it possible to achieve the desired range. Based on the entry conditions, the actual state vector, path and dynamic constraints, a reference trajectory is generated by the TPOS consisting of altitude-velocity profile, drag acceleration profile. Reference altitude and velocity profiles are calculated by integrating the Equations of Motion (EoM). A reference $\alpha$ profile is identified. The reentry energy corridor is then constructed based on the calculated upper and lower altitude/velocity limits. The necessary drag-energy profile is calculated and is used to determine the value of $\mu$. Based on the $\mu$ profile, the trajectory is integrated up to the TAEM interface and the cross-range at TAEM interface is estimated. The objective of bank reversal logic is to minimise such cross-range error. By applying $\alpha$ and $\mu$ modulation and integrating the EoM, the complete trajectory is generated. A 3-degrees-of-freedom (3-DoF) point mass model is assumed as main real-time model implemented in the VDPS for URSV re-entry dynamics. The EoM incorporate two control variables $\mathrm{u}=(\mu, \alpha)$. The six state variables are described as $\mathrm{x}=[\mathrm{r}, \theta, \varphi, \mathrm{V}, \gamma, \psi]$. The 3-DoF point mass model EoM, governing the vehicle states, are given by:

$$
\dot{r}=V \sin \gamma
$$




$$
\begin{aligned}
\dot{\theta} & =\frac{\mathrm{V} \cos \gamma \sin \psi}{\mathrm{r} \cos \varphi} \\
\dot{\varphi} & =\frac{\mathrm{V} \cos \gamma \cos \psi}{\mathrm{r}} \\
\dot{\mathrm{V}} & =-\mathrm{D}-\left(\sin \gamma / \mathrm{r}^{2}\right) \\
\dot{\gamma} & =\left(\frac{1}{\mathrm{~V}}\right)\left[\mathrm{L} \cos \mu+\left(\mathrm{V}^{2}-\frac{1}{\mathrm{r}}\right)\left(\frac{\cos \gamma}{\mathrm{r}}\right)\right] \\
\dot{\psi} & =\left(\frac{1}{\mathrm{~V}}\right)\left[\left(\frac{\mathrm{L} \sin \mu}{\cos \gamma}\right)+\left(\frac{\mathrm{V}^{2}}{\mathrm{r}}\right)(\cos \gamma \sin \psi \tan \varphi)\right]
\end{aligned}
$$

where ' $r$ ' is the radial distance from the centre of the Earth to the URSV in meters, ' $\theta$ ' is the geodetic longitude in radians, ' $\varphi$ ' is the geodetic latitude in radians, ' $V$ ' is the velocity in $\mathrm{m} / \mathrm{s}$ relative to the Earth surface, ' $\gamma$ ' is the flight path angle in radians and ' $\psi$ ' is the velocity azimuth angle in radians. The effect of wind and other atmospheric disturbances is assessed in the model validation. With the assumptions of no side-slip, non-rotating Earth and motion in vertical plane only (i.e., $\cos \mu=1$ ), the EoM are simplified. The path constraints pertaining to heat flux, dynamic pressure and g-load form the upper boundary of the entry corridor. In general, we have:

$$
\begin{aligned}
& \dot{\mathrm{Q}} \leq \mathrm{Q}_{\max } \\
& |\mathrm{L} \cos \alpha+\mathrm{D} \sin \alpha| \leq \mathrm{n}_{\text {max }}
\end{aligned}
$$

where ' $\dot{Q}_{\max }$ ' is the max heat flux in $W / m^{2}$, ' $n_{\max }$ ' is the max g-load factor, ' $L$ ' and ' $\mathrm{D}$ ' are the lift and drag aerodynamic accelerations in $\mathrm{m} / \mathrm{s}^{2}$. The lower boundary of the corridor is given by the steady glide equilibrium and the higher boundary of the corridor is given by the lower of the following maximum drag accelerations [9] expressed as:

$$
\left(\mathrm{g}-\frac{\mathrm{V}^{2}}{\mathrm{r}}\right) \frac{\mathrm{C}_{\mathrm{D}}}{\mathrm{C}_{\mathrm{L}}} \leq \mathrm{D} \leq \min \left\{\frac{\dot{\mathrm{Q}}_{\max }^{2} \mathrm{C}_{\mathrm{D}} \mathrm{S}}{2 \mathrm{~m} \mathrm{C}^{2} \mathrm{~V}^{4}} ; \frac{\mathrm{n}_{\max } \mathrm{g}}{\frac{\mathrm{C}_{\mathrm{L}}}{\mathrm{C}_{\mathrm{D}}} \cos \alpha+\sin \alpha} ; \frac{\mathrm{q}_{\max } \mathrm{C}_{\mathrm{D}} \mathrm{S}}{\mathrm{m}}\right\}
$$

where ' $\mathrm{q}_{\max }$ ' is the maximum dynamic pressure in $\mathrm{N} / \mathrm{m}^{2}$, ' $\mathrm{S}$ ' is the wing reference area in $\mathrm{m}^{2}$, ' $\mathrm{C}_{\mathrm{L}}$ ' is the lift coefficient, ' $\mathrm{C}_{\mathrm{D}}$ ' is the drag coefficient, ' $\mathrm{m}$ ' is the mass of the vehicle in $\mathrm{kg}$ and ' $\mathrm{g}$ ' is the acceleration due to gravity in $\mathrm{m} / \mathrm{s}^{2}$. The constant ' $\mathrm{C}$ ' is given by [9]:

$$
\mathrm{C}=\frac{\left(1.06584 \times 10^{8}\right)}{\sqrt{\mathrm{R}_{\mathrm{n}} \times \rho_{0}}} \frac{1}{(\mathrm{~g} \times \mathrm{r})^{1.5}}
$$

where ' $\rho_{0}$ ' is the Atmospheric density at sea level in $\mathrm{kg} / \mathrm{m}^{3}$ and ' $\mathrm{R}_{\mathrm{n}}$ ' is the vehicle nose radius in $\mathrm{m}$. A reference drag-acceleration profile is then generated such that the URSV lies within the entry corridor and takes into account a specified trajectory length. A 3-segment linear profile is adopted for the reference drag acceleration profile [9], where $D_{1}(E), D_{2}(E)$ and $D_{3}(E)$ are the three drag segments. $D_{i}$ and $D_{f}$ are the initial and final values of drag acceleration respectively. $E_{i}$ and $E_{f}$ are the initial energy at re-entry and the final energy at TAEM interface respectively. $\mathrm{D}_{c}$ is the constant drag of the intermediate segment. $E_{1}$ and $E_{2}$ are the energies corresponding to the boundary values of the constant drag. The trajectory length, ' $\mathrm{S}$ ' is given by:

$$
S=\int_{0}^{t} V d t=-\int_{E_{i}}^{E_{f}} \frac{1}{D(E)} d E=\frac{E_{1}-E_{i}}{D_{i}-D_{c}} \ln \frac{D_{c}}{D_{i}}+\frac{E_{1}-E_{2}}{D_{c}}+\frac{E_{f}-E_{2}}{D_{c}-D_{f}} \ln \frac{D_{f}}{D_{c}}
$$

By assuming an initial estimate of the trajectory length, the only unknown variable in the above equation is $D_{c}$, which is obtained by using the secant method [9]. Most of the re-entry algorithms assume a determined $\alpha$ profile. Though there is no specific method for determination of such profile, a general guideline is that $\alpha$ should be set close to its maximum value, $\alpha_{\text {max }}$ during the initial part of re-entry and it should be switched to $\alpha_{(\mathrm{L} / \mathrm{D})_{\max }}$ at a determined altitude before TAEM interface. The value of $\mu$ is derived from the constructed drag acceleration profile. The second derivative of drag acceleration with respect to energy is given by $[8,9]$ :

$$
\mathrm{D}^{\prime \prime}=\mathrm{a}+\mathrm{b}\left(\frac{\mathrm{L}}{\mathrm{D}}\right) \cos \mu
$$


where:

$$
\begin{aligned}
& \mathrm{a}=\mathrm{D}\left(\frac{\mathrm{C}_{\mathrm{D}}^{\prime \prime}}{\mathrm{C}_{\mathrm{D}}}-\frac{\mathrm{C}_{\mathrm{D}}^{\prime 2}}{\mathrm{C}_{\mathrm{D}}^{2}}\right)+\mathrm{D}^{\prime}\left(\frac{\mathrm{C}_{\mathrm{D}}^{\prime}}{\mathrm{C}_{\mathrm{D}}}+\frac{2}{\mathrm{~V}^{2}}\right)-\frac{4 \mathrm{D}}{\mathrm{V}^{4}}+\frac{1}{\mathrm{DV}^{2}}\left(-\frac{1}{\rho} \frac{\partial \rho}{\partial \mathrm{r}}+\frac{2 \mathrm{~g}}{\mathrm{~V}^{2}}\right)\left(\mathrm{g}-\frac{\mathrm{V}^{2}}{\mathrm{r}}\right) \\
& \mathrm{b}=-\frac{1}{\mathrm{~V}^{2}}\left(-\frac{1}{\rho} \frac{\partial \rho}{\partial \mathrm{r}}+\frac{2 \mathrm{~g}}{\mathrm{~V}^{2}}\right)
\end{aligned}
$$

The heading of the vehicle relative to the desired heading at TAEM interface is continuously monitored and whenever the difference between the two exceeds a predefined threshold, the direction of $\mu$ is reversed. For evaluating the states with respect to tolerance values, error analysis was performed on the trajectories obtained in the longitudinal profile considering velocity, altitude and flight path angle deviations from the nominal value. The $2 \sigma$ error parameters used in the stochastic case are from $[10,11]$ and the $3-\mathrm{DoF}$ vertical profile error parameters are expressed as:

$$
\begin{aligned}
& \sigma_{\dot{\mathrm{V}}}=\sqrt{\left(-\frac{1}{\mathrm{r}^{2}} \cos \gamma\right)^{2} \sigma_{\gamma}^{2}+\left(\frac{2 \sin \gamma}{\mathrm{r}^{3}}\right)^{2} \sigma_{\mathrm{r}}^{2}+\left(\frac{\rho \mathrm{V}^{2} \mathrm{~S}_{\mathrm{ref}} \mathrm{C}(\mathrm{D}, \alpha)}{2 \mathrm{~m}}\right)^{2} \sigma_{\alpha}^{2}} \\
& \sigma_{\dot{\mathrm{r}}}=\sqrt{(\sin \gamma)^{2} \sigma_{\mathrm{V}}{ }^{2}+(\mathrm{V} \cos \gamma)^{2} \sigma_{\gamma}{ }^{2}} \\
& \sigma_{\dot{\gamma}}=\sqrt{\left(\frac{\mathrm{L} \cos \mu}{\mathrm{V}^{2}}\right)^{2} \sigma_{\mathrm{V}}{ }^{2}+\left(-\frac{\mathrm{V} \cos \gamma}{\mathrm{r}^{2}}+\frac{\cos \gamma}{\mathrm{V} \cdot \mathrm{r}^{3}}\right)^{2} \sigma_{\mathrm{r}}{ }^{2}+\left(-\frac{\mathrm{V} \sin \gamma}{\mathrm{r}}+\frac{\sin \gamma}{\mathrm{V} \cdot \mathrm{r}^{2}}\right)^{2} \sigma_{\gamma}{ }^{2}+\left(\frac{\rho \mathrm{V}^{2} \mathrm{~S}_{\mathrm{ref}} \mathrm{C}_{(\mathrm{L}, \alpha)}}{2 \mathrm{~m}}\right)^{2} \sigma_{\mu}{ }^{2}}
\end{aligned}
$$

where ' $\rho$ ' is the atmospheric density in $\mathrm{kg} / \mathrm{m}^{3}$ and ' $\mathrm{S}_{\text {ref }}$ ' is the reference surface area of the URSV in $\mathrm{m}^{2}$.

\section{Simulation Results}

After the reference altitude-velocity profile has been constructed imposing $\alpha$ to be constant at $45^{\circ}$ and $\mu$ to zero, an entry corridor is identified in the drag-energy plane and the reference 3 segment drag acceleration profile is constructed for the vehicle under consideration as illustrated in Fig. 2. The upper boundary corresponds to the maximum heat flux and maximum g-loads. The lower boundary corresponds to the minimum lift. The updated $\alpha$ and $\mu$ profiles are obtained after the drag-energy profile is created. Angle of attack is set to a maximum of $45^{\circ}$ during the initial part of re-entry to minimize heating and modulated near the TAEM interface to obtain the maximum lift-to-drag ratio. The total range covered in the re-entry phase is $9378 \mathrm{~km}$. By using Monte Carlo sampling technique, the errors in the vertical profile are analysed for 100 samples and the mean and standard deviation $[2 \sigma]$ values obtained for altitude, velocity and flight path angle are $[21.29 \mathrm{~m}$, $1.9937 \mathrm{~m} / \mathrm{s}, 0.0000745 \mathrm{radian}]$ and [29.82 m, $2.4357 \mathrm{~m} / \mathrm{s}, 0.000616 \mathrm{radian}$ ] respectively. The results obtained from evaluating the errors demonstrate that the deviations are always well within the reentry energy corridor.

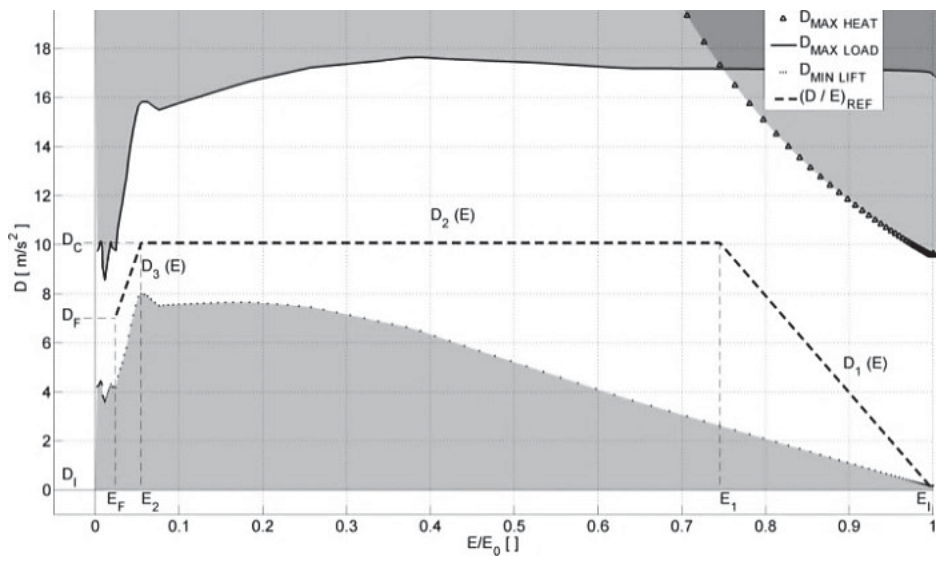

Fig. 2. Drag-energy profile construction. 


\section{Conclusions and Future Work}

The architecture of a Flight Management System (FMS) of an Unmanned Reusable Space Vehicle (URSV) was presented, with a special focus on functionalities for trajectory planning for atmospheric re-entry. The different flight phases of the space vehicle were identified and hypersonic re-entry and Terminal Area Energy Management (TAEM) were addressed as the two major phases of the atmospheric re-entry. A novel on-board trajectory planning algorithm based on the dragenergy profile was developed for the hypersonic re-entry phase. Angle of attack $(\alpha)$ and bank angle $(\mu)$ modulation were used to shape the re-entry trajectory. Simulation case studies were performed for the re-entry phase and the results demonstrated the FMS suitability to generate efficient trajectory profiles that satisfy the given constraints. Future work is envisaged in including all other flight phases including orbital flight and to address the future 4D Trajectory Based Operations (4DTBO) in an Environmentally Sustainable aviation (ESA) context [12].

\section{References}

[1] S. Liden, The Evolution of Flight Management Systems, AIAA/IEEE $13^{\text {th }}$ Digital Avionics Systems Conference, Phoenix, AZ, USA. (1994) DOI: 10.1109/DASC.1994.369487

[2] J. Sorensen, The Flight Planning - Flight Management Connection, Proceedings of the American Control Conference, San Diego, CA, USA. (1984)

[3] A. Herndon, M. Cramer, K. Sprong and R. Mayer, Analysis of Advanced Flight Management Systems (FMS), Flight Management Computer (FMC) Field Observations Trials, Vertical Path, $26^{\text {th }}$ Digital Avionics Systems Conference, Virginia, USA. (2007) DOI: 10.1109/DASC.2007.4391899

[4] J. Harpold and C. Graves, Shuttle Entry Guidance, Journal of the Astronautical Sciences, 37(3), pp. 239-268. (1979)

[5] J. Leavitt and K. Mease, Feasible Trajectory Generation for Atmospheric Entry Guidance, Journal of Guidance, Control and Dynamics, 30(2), pp. 473-481. (2007) DOI: 10.2514/1.23034

[6] Z. Shen and P. Lu, Onboard Generation of Three-Dimensional Constrained Entry Trajectories, Journal of Guidance, Control and Dynamics, 26(1), pp. 111-121. (2003) DOI: 10.2514/2.5021

[7] A. Saraf, J. Leavitt, D. Chen and K. Mease, Design and Evaluation of an Acceleration Guidance Algorithm for Entry, Journal of Spacecraft and Rockets, 41(6), pp. 986-996. (2004) DOI: $10.2514 / 1.11015$

[8] K. Mease, D. Chen, P. Teufel and H. Schonenberger, Reduced-Order Entry Trajectory Planning for Acceleration Guidance, Journal of Guidance, Control and Dynamics, 25(2), pp. 257-266. (2002) DOI: $10.2514 / 2.4906$

[9] M. Sangam, R. Sabatini, S. Ramasamy and A. Gardi, Advanced Flight Management System for an Unmanned Reusable Space Vehicle, International Journal of Unmanned Systems Engineering, 1(3), pp. 48-67. (2013) DOI: 10.14323/ijuseng.2013.11

[10] R. Sabatini, A. Kaharkar, C. Bartel and T. Shaid, Carrier-phase GNSS Attitude Determination and Control for Small UAV Applications, Journal of Aeronautics and Aerospace Engineering, 2(4). (2013) DOI: 10.4172/2168-9792.1000120

[11] R. Sabatini, M.A. Richardson, C. Bartel, A. Kaharkar, T. Shaid, L. Rodriguez and A. Gardi, A Low-cost Vision Based Navigation System for Small Size Unmanned Aerial Vehicle Applications, Journal of Aeronautics and Aerospace Engineering, 2(3). (2013) DOI: 10.4172/2168-9792.1000110

[12] S. Ramasamy, R. Sabatini, A. Gardi and Y. Liu, Novel Flight Management System for Real Time 4-Dimensional Trajectory Based Operations, AIAA Guidance, Navigation \& Control Conference, Boston, Massachusetts, USA. (2013) DOI: 10.2514/6.2013-4763 